\title{
A study of the vitreoretinal interface in patients with age-related macular degeneration
}

\section{Estudo da interface vitreorretiniana em pacientes com degeneração macular relacionada à idade}

\author{
Maíra de França Martins ${ }^{1}$, Edio Volpatto ${ }^{2}$, Paula Emery ${ }^{3}$, Pedro Duraes Serracarbassa ${ }^{3}$
}

\begin{abstract}
Purpose: To assess whether hyaloid adhesion is more prevalent in patients with age-related macular degeneration (AMD) than in control patients and to evaluate whether it is more prevalent in exudative AMD than in non-exudative AMD.

Methods: This was a cross-sectional, controlled analytical study. Patients from the Ophthalmology Department of the Public Service Hospital of the State of São Paulo were included if they were diagnosed with AMD that was confirmed by fundus biomicroscopy and fluorescein angiography. Patients were divided into three groups: patients without a vitreoretinal disease (controls), patients with exudative AMD, and patients with non-exudative AMD. For the optimal study of the vitreoretinal interface, all patients were subjected to spectral-domain optical coherence tomography (SD-OCT; Cirrus HD-OCT, version 4000; Carl Zeiss Meditec) and ultrasonography (UltraScan ${ }^{\circledR}$, Alcon). Results with p values of $\leq 0.05$ were considered statistically significant.

Results: We assessed 75 eyes of 23 patients with AMD ( 14 women and nine men) and 15 the control patients ( 11 women and four men). In total, 33 eyes had AMD that was consistent with the inclusion criteria, of which 11 had the non-exudative form (non-atrophic) and 22 had the exudative form (11 active and 11 disciform scars). Adherence was observed in eight eyes in the control group (26.67\%), in seven eyes with exudative AMD (31.82\%), and in five eyes with non-exudative AMD (45.45\%).

Conclusion: Patients with exudative and non-exudative forms of AMD did not present with higher vitreoretinal adhesion than control patients as assessed by SD-OCT and ultrasound. Moreover, patients with exudative AMD (neovascular membrane and disciform scar) did not reveal a higher adherence than those with non-exudative AMD when evaluated by the same methods.
\end{abstract}

Keywords: Macular degeneration/ultrasonography; Macula lutea; Tomography optical coherence/methods; Tissue adhesion

\section{RESUMO}

Objetivo: Avaliar se a adesão hialoidea é mais prevalente em pacientes com degeneração macular relacionada a idade (DMRI) (exsudativa e não exsudativa) comparado ao grupo controle e avaliar se a prevalência é maior na forma exsudativa comparada a forma não exsudativa.

Métodos: Trata-se de um estudo transversal, analítico, de grupo controle, com os pacientes atendidos no Departamento de Retina do Serviço de Oftalmologia do Hospital do Servidor Público Estadual de São Paulo (HSPE), que tiveram o diagnóstico de DMRI confirmado após a biomicroscopia de fundo e angiofluoresceinografia. Os pacientes foram divididos em três grupos, um composto por pacientes sem doenças vitreorretinianas (30 olhos), outro pacientes com DMRI exsudativa (22 olhos) e o terceiro grupo por pacientes com DMRI não exsudativa (11 olhos). Para melhor estudo da interface vitreorretiniana, todos os pacientes foram submetidos aos exames de SD-TCO (Cirrus HD-TCO, versão 4000; Carl Zeeis Meditec) e ultrassonografia (UItraScan ${ }^{\oplus}$, Alcon). Foram considerados significativos os resultados com valor de $p \leq 0,05$.

Resultados: Foram avaliados 75 olhos de 23 pacientes com DMRI e 15 no grupo controle, sendo que apenas 33 olhos que apresentavam DMRI obedeciam aos critérios de inclusão, sendo 11 pertencentes à forma seca (nenhuma forma atrófica) e 22 à forma exsudativa (11 de forma ativa e 11 disciforme). A adesäo foi encontrada em oito olhos no grupo controle (26,67\%), em sete olhos com DMRI exsudativa $(31,82 \%)$ e em cinco olhos no grupo DMRI não exsudativa (45,45\%).

Conclusão: Neste estudo, pacientes com DMRI (formas exsudativa e não exsudativa) não apresentaram maior adesão vitreorretiniana quando comparados ao grupo controle, ao serem avaliados através SD-TCO (Cirrus HD-TCO, versão 4000; Carl Zeeis Meditec) e ultrassonografia (UltraScan ${ }^{\oplus}$, Alcon). Neste estudo, pacientes com DMRI exsudativa (ativa e disciforme) não apresentaram maior adesão quando comparados à forma seca, ao serem avaliados pelos mesmos métodos.

Descritores: Degeneração macular/ultrassonografia; Macula lútea; Tomografia de coerência óptica/métodos; Aderências teciduais

\section{INTRODUCTION}

Age-related macular degeneration (AMD) is a disease initially characterized by the presence of drusen and abnormal pigmentation of the retinal pigment epithelium (RPE) and later by geographic atrophy, choroidal neovascularization, RPE detachment, and fibrosis. Of the four leading causes of blindness, AMD is the only one for which prophylaxis and treatment remains unclear. This is mainly because of a lack of knowledge with regard to its etiology and pathophysiological mechanisms involved in the different stages of the disease ${ }^{(1)}$. Currently, there are several treatments; however, none of these appear to be sufficiently effective. Therefore, a more extensive study of AMD pathophysiology is necessary to optimize treatment ${ }^{(2-9)}$.

AMD appears to be a multifactorial disease. Genetics is likely to play a key role in its occurrence; furthermore, oxidative stress, ischemia, aging of RPE, and inflammation were other possible etiological factors ${ }^{(10,11)}$. A tyrosine-histidine change at the 402th amino acid position in the
Submitted for publication: May 27, 2015

Accepted for publication: November 6, 2015

Curitiba, Paraná, PR, Brazil.

Campo Grande, Mato Grosso do Sul, MS, Brazil.

${ }^{3}$ Department of Ophthalmology, Retina section, Hospital do Servidor Público do Estado de São Paulo, HSPE, São Paulo, SP, Brazil.
Funding: No specific financial support was available for this study.

Disclosure of potential conflicts of interest: None of the authors have any potential conflicts of interest to disclose.

Corresponding author: Maíra de França Martins. Rua Capitão Souza Franco, 95 - Curitiba, PR 80730-420 - Brazil - E-mail: mairafranca@hotmail.com

Approved by the following research ethics committee: Hospital do Servidor Público do Estado de São Paulo. CEEA: 17729713.0.0000.5463. 
complement factor $\mathrm{H}$ on the chromosome 1 is strongly associated with $\mathrm{AMD}^{(12-14)}$, along with factors such as race, age, and smoking. An inflammatory cycle is also believed to be involved (including immune complex formation, complement activation, extracellular matrix proteolysis, and choroidal T cell and other cell activations), which damages RPE with concomitant degeneration of photoreceptor cells that can extend into more internally located retinal layers.

Although AMD primarily comprises the external layers of the retina, the vitreous may play a role in its etiopathogenesis and/or progression and that inflammation most likely begins in RPE and may even reach the vitreoretinal interface ${ }^{(15)}$. Moreover, some reports have demonstrated a higher rate of vitreoretinal adhesion in $\mathrm{AMD}^{(16-22)}$, perhaps contributing to the unfavorable evolution in some cases and/or an insignificant response to intravitreal anti-vascular endothelial growth factor (anti-VEGF).

This study aimed to assess whether hyaloid adhesion is more prevalent in patients with AMD than in control patients and to evaluate whether the prevalence is higher in exudative or non-exudative AMD.

\section{METHODS}

This is a cross-sectional analytical study with a control group. Patients were recruited from the Ophthalmology Department of the Public Service Hospital of the State of São Paulo. Patients who received a diagnosis of AMD that was confirmed by fundus biomicroscopy and fluorescein angiography from May 2010 to November 2014 were included. Eyes in all stages of non-exudative (drusen, pigment alterations, and atrophy) and exudative AMD (active or disciform scar) were included. The study was approved by the Ethics Committee of Hospital do Servidor Público do Estado de São Paulo and all patients read and then signed a consent form prior to the initiation of the study.

We excluded all patients presenting with other vitreoretinal afflictions concomitant with AMD and/or previous eye surgery and/or any previous intraocular treatment, such as laser or intravitreal injection and/or previous history of ocular trauma or myopia equal or higher than two diopters.

For optimal study of the vitreoretinal interface, all patients underwent ultrasonography (USG; UltraScan ${ }^{\circledR}$, Alcon) and spectral-domain optical coherence tomography (SD-OCT) imaging (Cirrus HD-OCT, version 4000; Carl Zeiss Meditec). All USG examinations were performed by the same examiner using the transpalpebral contact technique with a $10-\mathrm{MHz}$ probe and $75-\mathrm{dB}$ gain in modes $\mathrm{A}$ and $\mathrm{B}$. SD-OCT was performed by a different examiner following drug-induced mydriasis (10\% phenylephrine, 3 drops); however, with respect to the USG examinations, all procedures were performed by the same examiner. We used the 5-line raster scan mode (4,096 A-scans on each of the five lines) and Macular Cube $512 \times 128$. Only the macular area was evaluated.

Adherence was considered when an average reflectivity line was observed to be partially adherent to the nerve fiber layer. Adhesion was excluded when this line was observed above the nerve fiber layer. When the line was not observed, USG was evaluated to determine whether the hyaloid was anterior or not detached. We considered adherence to be present when the hyaloid was visually adherent to the retinal surface of the macular area in SD-OCT, when it was visually adherent to the macula in USG and SD-OCT, and when the hyaloid was not visible by either method. Non-adherence was considered when the hyaloid was visually non-adherent to the retinal surface in the macular area in the SD-OCT, when it was visually non-adherent to the macula in USG and SD-OCT, whether by total or partial hyaloid detachment (adherent to the optic nerve).

For comparative analysis, we selected patients without vitreoretinal alterations, with similar average ages, and who did not meet the exclusion criteria.

To investigate the relationship between vitreoretinal adhesion and AMD, we performed a non-parametric Fisher's exact test consi- dering two forms of the disease: exudative (active membrane or disciform scar) and non-exudative AMD (drusen or geographic atrophy), with a third group serving as the control. Age uniformity was verified by analysis of variance $(F=1.959, p=0.131)$. Results with $p$ values of $\leq 0.05$ were considered statistically significant.

\section{RESULTS}

We assessed 75 eyes of 23 patients with AMD (14 women and nine men) and 15 in control group ( 11 women and four men). In total, 33 eyes had AMD that was consistent with the inclusion criteria; of which 11 had the non-exudative form (non-atrophic) and 22 had the exudative form (11 active and 11 disciform scars).

In the AMD group, we observed two patients with the non-exudative form in one eye each and the disciform scar in the contralateral eye, one patient with disciform scars in both eyes, three patients with the non-exudative form in one eye each and a choroidal neovascular membrane (CNVM) in the other eye, five patients with disciform scars in one eye each and CNVM in the other eye, one patient with the nonexudative form in both eyes, and one patient with CNVM in both eyes.

Twelve eyes were excluded from the study for the following reasons: Ten were pseudophakic (three disciform, one atrophic, and six active (NVM) and two had already received an anti-VEGF injection. One was excluded for having received intravitreal injections (active form) and another for undergoing laser treatment (disciform scar).

The average age of the patients was similar across the groups (Table 1).

All eyes were assessed by SD-OCT and USG in a complementary manner, and adhesion was found in $7 / 22$ (31.82\%) eyes with exudative $A M D$, in 5/11 (45.45\%) eyes with non-exudative AMD, and in 8/30 $(26.67 \%)$ eyes in the control group. Non-adhesion was diagnosed in $15 / 22$ (68.18\%) eyes with exudative AMD, in 6/11 (54.55\%) eyes with non-exudative AMD, and in 22/30 (73.33\%) eyes within the control group (Table 2). While separately evaluating cases of exudative AMD, we found adhesion in 6/22 (27.27\%) eyes with active neovascular membranes and in 1/22 (4.54\%) eyes with disciform scars. Adhesion was absent in 5/22 (22.72\%) eyes with active neovascular membranes and in 10/22 (45.45\%) eyes with disciform scars.

Table 1. Average age, standard deviation, and $95 \%$ confidence intervals for patients in each study group. Analysis of variance $(F=1.959$, $p=0.131$ ) was used for verification, and no difference in age was observed the three groups

\begin{tabular}{lcc}
\hline Group & Average \pm standard deviation & 95\% confidence interval \\
\hline Control & $69.64 \pm 6.19$ & $67.24-72.04$ \\
Dry AMD & $77.18 \pm 9.61$ & $70.72-83.64$ \\
Exudative AMD & $72.45 \pm 11.64$ & $67.01-77.90$
\end{tabular}

${ }^{1} \mathrm{AMD}=$ age-related macular degeneration.

Table 2. Comparison ${ }^{1}$ of vitreoretinal adhesion rates between age-related macular degeneration (AMD) and control groups

\begin{tabular}{lccc}
\hline & \multicolumn{2}{c}{ Vitreoretinal adhesion } & \\
\cline { 2 - 3 } Group & Adhesion & No adhesion & Total \\
\hline Control & $8(26.67 \%)$ & $22(73.33 \%)$ & 30 \\
Exudative AMD $(p=0.762)$ & $7(31.82 \%)$ & $15(68.18 \%)$ & 22 \\
Dry AMD $(p=0.280)$ & $5(45.45 \%)$ & $6(54.55 \%)$ & 11 \\
Total & 20 & 43 & 63 \\
\hline
\end{tabular}

'Absolute frequency and percentage within each group [control, non-exudative agerelated (dry) macular degeneration and exudative age-related macular degeneration] related to vitreoretinal adhesion, evaluated by spectral domain optical coherence tomography and ultrasonography. 
In six patients with $\mathrm{AMD}$, SD-OCT revealed vitreoretinal adhesion (Figure 1), whereas USG detected two cases of partial posterior vitreous detachment (PVD), with both being adherent to the macula, as shown in figure 2 (in four cases, there was no PVD). In the 25 cases of AMD in which the hyaloid was not visible by SD-OCT (Figure 3), USG detected total PVD in five eyes, mobile vitreous membranes in six eyes, and partial PVD in 14 eyes (adherent to the optic nerve). In one of the two cases in which SD-OCT revealed total detachment of the hyaloid in the macular area, while USG revealed no detachment.

USG detected mobile vitreous membranes in all nine cases in the control group that had hyaloid adhesion in the macula on SD-OCT examination. In 19 cases in which the hyaloid was not visualized in SD-OCT, USG detected eight cases of partial PVD (adherent to the optic nerve), eight cases of total PVD, and three cases with mobile vitreous membranes. In the two cases in which the hyaloid was non-adherent, USG revealed partial PVD in one case (adherent to the optical nerve) and total PVD in the other case.

Moreover, vitreoretinal adhesion was not associated with AMD presence. The proportion of patients with and without adhesion who were evaluated by SD-OCT and USG did not differ between the AMD (non-exudative and exudative) and control groups $\left(X^{2}=0.682\right.$;

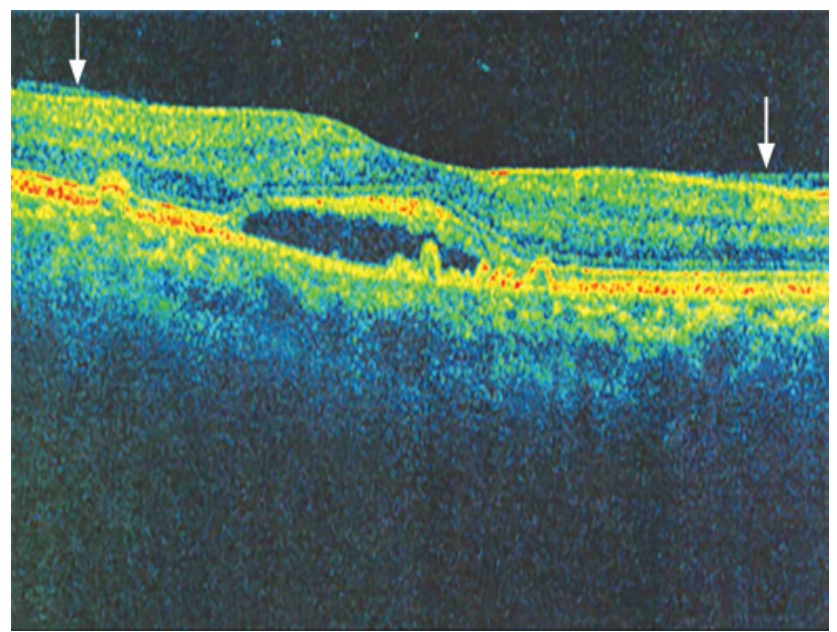

Figure 1. Image obtained with spectral domain optical coherence tomography (Cirrus HD-OCT), showing the hyaloid adhering to the macular area (arrows).

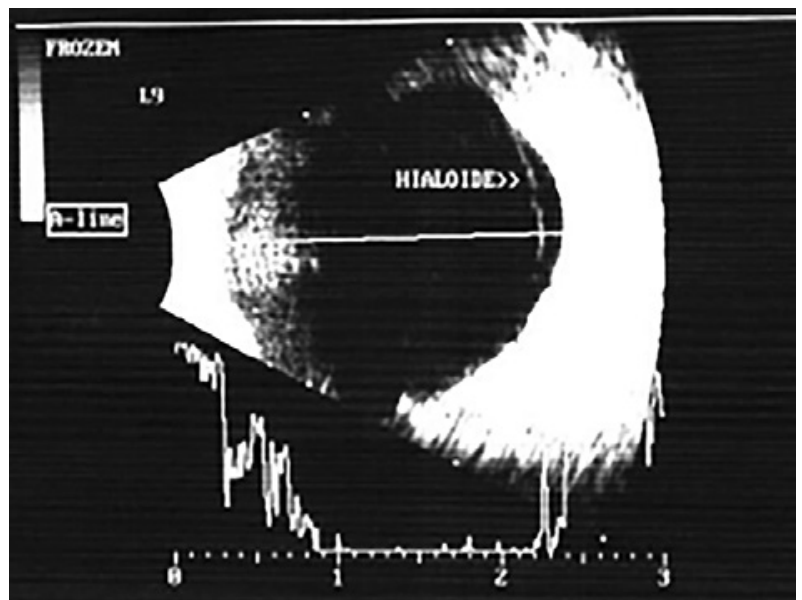

Figure 2. Image obtained by ultrasonography using a 10-MHz transducer. The hyaloid adhering to the neovascular membrane is visible. $\mathrm{p}=0.432)$. Thus, given the study conditions, vitreoretinal adhesion was neither higher nor lower in patients with AMD than in control patients.

The proportion of patients with and without adhesion who were evaluated by SD-OCT and USG did not differ between the non-exudative and exudative AMD groups $\left(X^{2}=0.589 ; p=0.471\right)$. Thus, given the study conditions, vitreoretinal adhesion was neither higher nor lower in patients with the exudative form than in those with the non-exudative form.

The proportion of patients with and without adhesion who were evaluated by OCT and US did not differ between the non-exudative AMD and control groups $\left(X^{2}=1.312, p=0.280\right)$ or between the exudative AMD and control groups $\left(X^{2}=0.164, p=0.762\right)$.

\section{DISCUSSION}

There is still much speculation regarding the role of hyaloid in AMD. The vitreous is an important component in the pathophysiology of several retinal diseases, and hyaloid adhesion is a poor prognostic factor in some. Consequently, questions have been raised regarding the supposed role of hyaloid adhesion in AMD, with several theories being postulated. On the one hand, hyaloid adhesion has been only considered as a risk factor of AMD progression, whereas on the other hand, it has been only considered to be part of its pathophysiology. In other studies, it has been considered as a poor prognostic factor, predisposing either to the development of the exudative form or to a worse response to treatment.

Some studies suggest that hyaloid adhesion may induce a mild chronic retinal inflammation ${ }^{(18,19)}$. This is then posited to hinder oxygen penetration and to cause chronic ischemia or VEGF retention in the macular area. Furthermore, hyaloid traction may lead to RPE disruption, which is known to induce the appearance of the neovascular membrane. Embryological, molecular, and structural similarities have been demonstrated between Bruch's membrane and the internal limiting membrane, thus supporting the theory that hyaloid may play a role in $\mathrm{AMD}^{(23)}$

We assessed the presence of vitreoretinal adhesion in patients with AMD to test its prevalence against that of a control group. When the hyaloid detachment develops close to the retina, the presence of vitreoretinal adhesion or traction can be difficult to diagnose using USG; therefore, we used SD-OCT for optimal assessment. However, SD-OCT images in cases with either total hyaloid adhesion in the macular area or total detachment with hyaloid anteriorization are similar (the hyaloid is invisible); thus, the use of USG becomes indispensable.

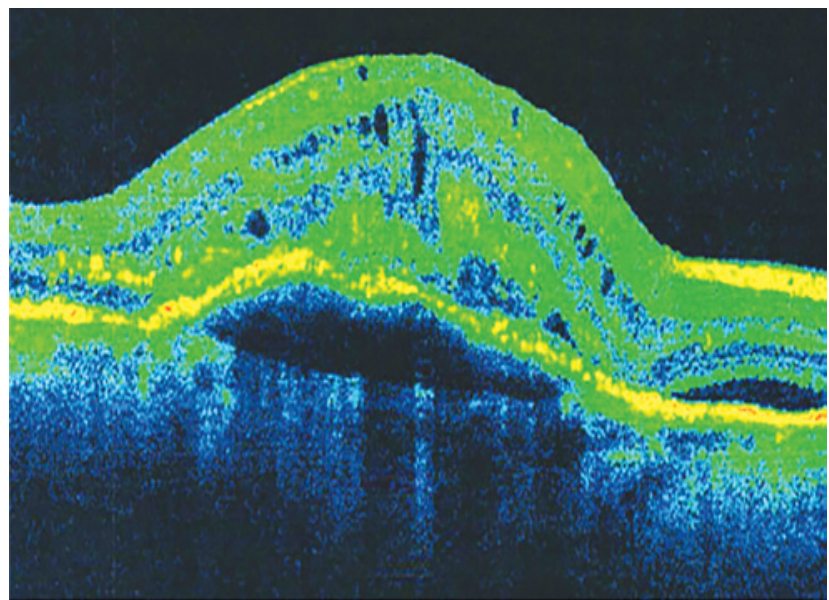

Figure 3. Image obtained by spectral domain optical coherence tomography (Cirrus $\mathrm{HD}-\mathrm{OCT}$ ). The hyaloid is not evident. 
Furthermore, we chose not to distinguish between adhesion and traction because it has already been performed in some studies. Therefore, the objective was limited to assessing whether the prevalence of adherent hyaloid was higher in patients with AMD than in patients of the same age without AMD because it is known that the incidence of PVD increases with age.

In this analysis, we did not observe a higher vitreoretinal adhesion in patients with AMD than in the control patients, and we did not determine higher adhesion rates in patients with the exudative form than in those with the non-exudative form.

However, the evidence for a higher prevalence of vitreous adhesion in AMD remains conflicting. Some studies demonstrated higher hyaloid adhesion at all stages of AMD ${ }^{(17,19,20)}$, whereas others demonstrated higher adhesion rates in the initial phases only ${ }^{(18)}$.

Vitreomacular adhesion was assessed in patients with $\mathrm{AMD}^{(17)}$ by dividing patients into exudative AMD, non-exudative AMD, and control groups. The presence of hyaloid adhesion in the macular area was analyzed by OCT/confocal scanning laser ophthalmoscopy, whereas the presence of total PVD was evaluated by fundus biomicroscopy. Adhesion in patients with AMD was higher than in control patients; however, there was no difference between patients with exudative AMD and those with non-exudative AMD.

In another study ${ }^{(20)}$, patients were divided in the same manner; however, only the presence of total PVD was assessed with USG. This approach also led to identifying a higher percentage of total PVD in the control group; however, no difference was observed when nonexudative and exudative AMD were compared.

In another analysis (24), when adhesion was assessed by SD-OCT (Spectralis OCT ${ }^{\mathrm{TM}}$; Heidelberg Engineering, Heidelberg, Germany) and fundus biomicroscopy in patients with active exudative AMD only, the result was different because of the higher rate of non-adhesion within the study group.

Another study ${ }^{(25)}$ evaluated cases of non-exudative AMD that were classified as high risk (i.e., category IV according to the Age-Related Disease Study) using patients with a CNVM in one eye and nonexudative high-risk AMD in the contralateral eye. Hyaloid adhesion was assessed by the time-domain OCT (OCT3, Carl Zeiss, Meditech, Dublin, CA), SD-OCT (Cirrus Version, Carl Zeiss) and the presence of the Weiss ring on biomicroscopy examination, thus concluding that there was no significant influence of vitreomacular adhesion on the development of the exudative form.

Furthermore, another study with a similar design ${ }^{(22)}$ assessed hyaloid adhesion by SD-OCT (Stratus OCT3, Zeiss Humphrey, San Leandro, (A) in patients with CNVM in one eye and no signs of CNVM or drusen in the contralateral eye. The authors concluded that vitreoretinal adhesion might be a risk factor for exudative AMD because most eyes with adhesion exhibited active exudative AMD.

In another study ${ }^{(19)}$, patients were divided in a similar manner as in previous studies ${ }^{(17,20)}$ but with the control group comprising contralateral eyes, as detailed elsewhere ${ }^{(22,25)}$. Using USG and SD-OCT (Stratus III, Carl Zeiss, San Leandro, California, USA) to verify the status of the hyaloid, the authors discovered higher adhesion rates in patients with exudative AMD than in controls and patients with non-exudative AMD.

In an alternative assessment of hyaloid adhesion in $\mathrm{AMD}^{(18)}$, two groups were formed; one with druse in one eye and CNVM in the contralateral eye and another with atrophy in one eye and disciform disease in the contralateral eye. The presence of vitreomacular adhesion was evaluated by SD-OCT (OCT-SLO, OCT1000, and Stratus III OCT), and the presence of PVD was evaluated by USG. Similar to a previous study ${ }^{(22)}$, it was concluded that total PVD might be protective against CNVM, whereas adhesion may be a risk factor for CNVM.

Further, in an evaluation of cases of CNVM using SD-OCT (OCT3, Carl Zeiss) (21), it was reported that most cases presented with abnormalities in the vitreoretinal interface.

When analyzing the existing studies, one will notice contradictory and inconclusive results, with many different methodologies, apparatuses, and groups being analyzed.
Given the results of this study, we believe that the hyaloid does not have a significant role in AMD pathophysiology. However, in cases of adhesion and CNVM, we observed that the hyaloid was always adherent in the membrane area, suggesting that a relationship could indeed exist between CNVM and hyaloid adhesion, as demonstrated in other studies ${ }^{(15,18,19,21,22)}$.

A possible explanation is that a more intense retinal inflammation could be present in some cases of exudative AMD.

Nevertheless, questions remain as to whether such an inflammation would be a cause or consequence. Similarities in molecular composition and structural organization of the vitreoretinal interface and between the retina and RPE suggest that both interfaces may be subject to the same aging processes and that abnormalities of the first may alter or amplify the degenerative processes of the latter and vice-versa ${ }^{(23)}$.

In this study, AMD stages (CNVM vs. disciform) were not separately evaluated; however, the percentage of adhesion in eyes with CNVM (27.7\%) was higher than in eyes with disciform disease (4.54\%). We failed to determine higher adhesion rates in the exudative group because of perhaps the high incidence of non-adhesion in the disciform group (10/22).

Moreover, it is possible that hyaloid detachment is a natural process in AMD evolution, such as atrophy and disciform scar formation, which develops once the appearance of Muller cells would affect the integrity of the internal limiting membrane, thereby promoting hyaloid detachment. This hypothesis is consistent with previous observations ${ }^{(18)}$ and with our finding that adhesion occurred in $27.7 \%$ of the eyes with CNVM and in only $4.54 \%$ of those with disciform disease. However, further discussion is beyond the scope of this paper.

As demonstrated by a few studies, the hyaloid may only act as a poor prognostic factor for improving visual acuity following treatment, particularly when there is a traction in the macular area ${ }^{(24,26-28)}$. In those cases, there is a disruption of the retinal layers that was caused not only by CNVM but also by hyaloid traction, thus leading to a worse visual prognosis. Alternatively, if the hypothesis of inflammation equally developing in the vitreoretinal interface and between the retina and RPE is confirmed, it would be conceivable that more severe degrees of inflammation result in both CNVM and in adhesion/traction/epiretinal membranes, as observed in a study ${ }^{(21)}$. To improve visual prognosis of those cases, removal of the hyaloid may be justifiable.

We believe that despite the limited sample size of this study, the role of the hyaloid remains questionable. Further research must continue with greater degrees of standardization in the groups evaluated and in the methods used.

It is important to pay special attention to the study of the hyaloid in cases with high-risk non-exudative AMD, as performed by a previous study ${ }^{(25)}$, particularly before recommending vitrectomy as a preventive measure against CNVM or macular atrophy ${ }^{(29)}$.

Thus, it must be evaluated whether performing vitrectomy would adequately treat AMD. Finally, it is necessary to clarify whether removing the vitreous would reduce the incidence of AMD or just that of CNVM or if it would affect visual prognosis.

\section{CONCLUSION}

In this study, when assessed by SD-OCT and USG, patients with exudative and non-exudative forms of AMD did not present with higher vitreoretinal adhesion than control patients without AMD. Moreover, exudative AMD (CNVM and disciform) was not associated with higher levels of adhesion when compared with non-exudative AMD.

\section{REFERENCES}

1. Stefánsson E, Geirsdóttir A, Sigurdsson H. Metabolic physiology in age related macular degeneration. Prog Retin Eye Res. 2011;30(1):72-80.

2. Rosenfeld PJ, Moshfeghi AA, Puliafito CA. Optical coherence tomography findings after an intravitreal injection of bevacizumab (avastin) for neovascular age-related macular 
degeneration. Ophthalmic Surg Lasers Imaging. 2005;36(4):331-5. Comment in: Ophthalmic Surg Lasers Imaging. 2005;36(4):270-1.

3. Heier JS, Brown DM, Chong V, Korobelnik JF, Kaiser PK, Nguyen QD, Kirchhof B, Ho A, Ogura Y, Yancopoulos GD, Stahl N, Vitti R, Berliner AJ, Soo Y, Anderesi M, Groetzbach G, Sommerauer B, Sandbrink R, Simader C, Schmidt-Erfurth U; VIEW 1 and VIEW 2 Study Groups. Intravitreal aflibercept (VEGF trap-eye) in wet age-related macular degeneration. Ophthalmology. 2012;119(12):2537-48. Erratum in: Ophthalmology. 2013;120(1):209-10. Comment in: Ophthalmology. 2014;121(1):e5-6; Ophthalmology. 2014;121(1):e4; Ophthalmology. 2014;121(1):e5; Ophthalmology. 2014;121(1):e5-6.

4. Morales-Canton V, Quiroz-Mercado H, Velez-Montoya R, Zavala-Ayala A, Moshfeghi AA, Shusterman EM, et al. 16 and 24 Gy Low-voltage X-ray irradiation with ranibizumab therapy for neovascular age-related macular degeneration: 12-month outcomes. Am J Ophthalmol. 2013;155(6):1000-8.e2.

5. Laser photocoagulation of subfoveal neovascular lesions of age-related macular degeneration. Updated findings from two clinical trials. Macular Photocoagulation Study Group. Arch Ophthalmol. 1993;111(9):1200-9. Comment in: Arch Ophthalmol. 1994;112(7):874-5.

6. Bressler NM, Chang TS, Suñer IJ, Fine JT, Dolan CM, Ward J, lanchulev T; MARINA and ANCHOR Research Groups. Vision-related function after ranibizumab treatment by better- or worse-seeing eye: clinical trial results from MARINA and ANCHOR. Ophthalmology. 2010;117(4):747-56.e4.

7. Sternberg P Jr, Lewis H. Photodynamic therapy for age-related macular degeneration: a candid appraisal. Am J Ophthalmol. 2004;137(3):483-5.

8. Spaide RF, Sorenson J, Maranan L. Photodynamic therapy with verteporfin combined with intravitreal injection of triamcinolone acetonide for choroidal neovascularization. Ophthalmology. 2005;112(2):301-4.

9. Gragoudas ES, Adamis AP, Cunningham ET Jr, Feinsod M, Guyer DR; VEGF Inhibition Study in Ocular Neovascularization Clinical Trial Group. Pegaptanib for neovascular age-related macular degeneration. N Engl J Med. 2004;351(27): 2805-16. Comment in: ACP J Club. 2005;143(1):18. N Engl J Med. 2004;351(27):2863-5. N Engl J Med. 2005; 352(16):1720-1; author reply 1720-1.

10. Traboulsi El. The challenges and surprises of studying the genetics of age-related macular degeneration. Am J Ophthalmol. 2005;139(5):908-11. Comment on: Am J Ophthalmol. 2005;139(5):820-5.

11. Weeks DE, Conley YP, Tsai HJ, Mah TS, Schmidt S, Postel EA, et al. Age-related maculopathy: a genomewide scan with continued evidence of susceptibility loci within the 1q31, 10q26, and 17q25 regions. Am J Hum Genet. 2004:75(2):174-89.

12. Klein RJ, Zeiss C, Chew EY, Tsai JY, Sackler RS, Haynes C, et al. Complement factor $H$ polymorphism in age-related macular degeneration. Science. 2005;308(5720):385-9. Comment in: Science. 2005:308(5720):362-4.

13. Edwards AO, Ritter R $3^{\text {rd }}$, Abel KJ, Manning A, Panhuysen C, Farrer LA. Complement factor $\mathrm{H}$ polymorphism and age-related macular degeneration. Science. 2005; 308(5720):421-4. Comment in: Science. 2005;308(5720):362-4.
14. Haines JL, Hauser MA, Schmidt S, Scott WK, Oslon LM, Gallins P, et al. Complement factor $\mathrm{H}$ variant increases the risk of age-related macular degeneration. Science. 2005; 308(5720):419-21. Comment in: Science. 2005;308(5720):362-4.

15. Krebs I, Glittenberg C, Zeiler F, Binder S. Spectral domain optical coherence tomography for higher precision in the evaluation of vitreoretinal adhesions in exudative age-related macular degeneration. Br J Ophthalmol. 2011;95(10):1415-8.

16. Krebs I, Hagen S, Haas P, Glittenberg C, Binder S. The vitreo-retinal interface in macular diseases. Spektrum Augenheilkd. 2009:23:2-11.

17. Mojana F, Cheng L, Bartsch DU, Silva GA, Kozak I, Nigam N, et al. The role of abnormal vitreomacular adhesion in age-related macular degeneration: spectral optical coherence tomography and surgical results. Am J Ophthalmol. 2008;146(2):218-27. Comment in: Am J Ophthalmol. 2009;147(2):375-6; author reply 376-7.

18. Robison CD, Krebs I, Binder S, Barbazetto IA, Kotsolis Al, Yannuzzi LA, et al. Vitreomacular adhesion in active and end-stage age-related macular degeneration. Am J Ophthalmol. 2009;148(1):79-82.

19. Krebs I, Brannath W, Glittenberg C, Zeiler F, Sebag J, Binder S. Posterior vitreomacular adhesion: a potential risk factor for exudative age-related macular degeneration? Am J Ophthalmol. 2007;144(5):741-6. Comment in: Am J Ophthalmol. 2008;145(4):765; author reply 765-6; Am J Ophthalmol. 2008;145(4):765; author reply 765-6.

20. Ondes F, Yilmaz G, Acar MA, Unlü N, Kocaoðlan H, Arsan AK. Role of the vitreous in age-related macular degeneration. Jpn J Ophthalmol. 2000;44(1):91-3.

21. Quaranta-El Maftouhi M, Mauget-Faÿsse M. Anomalous vitreoretinal adhesions in patients with exudative age-related macular degeneration: an OCT study. Eur J Ophthalmol. 2006;16(1):134-7.

22. Lee SJ, Lee CS, Koh HJ. Posterior vitreomacular adhesion and risk of exudative age-related macular degeneration: paired eye study. Am J Ophthalmol. 2009;147(4):621-6.

23. Sebag J, Hageman GS. Interfaces. Eur J Ophthalmol. 2000;10:1-3.

24. Veloso CE, Nehemy MB. Efeito da adesão vitreomacular no tratamento da degeneração macular relacionada à idade com antiangiogênicos [Internet]. São Paulo: Hospital das Clinicas, Clinica Oftalmológica [citado 2011 Mar 3]. Disponível em: http:// oftalmologiausp.com.br/ePoster/PDF01.html

25. Waldstein SM, Sponer U, Simader C, Sacu S, Schmidt-Erfurth U. Influence of vitreomacular adhesion on the development of exudative age-related macular degeneration: 4-year results of a longitudinal study. Retina. 2012;32(3):424-33.

26. Green-Simms AE, Bakri SJ. Vitreomacular traction and age-related macular degeneration. Semin Ophthalmol. 2011;26(3):137-8.

27. Lee SJ, Koh HJ. Effects of vitreomacular adhesion on antivascular endothelial growth factor treatment for exudative age-related macular degeneration. Ophthalmology. 2011;118(1):101-10.

28. Schulze $S$, Hoerle $S$, Mennel S, Kroll P. Vitreomacular traction and exudative age-related macular degeneration. Acta Ophthalmol. 2008;86(5):470-81.

29. Roller AB, Mahajan VB, Boldt HC, Abramoff MD, Russell SR, Folk JC. Effects of vitrectomy on age-related macular degeneration. Ophthalmology. 2010;117(7):1381-6. 